confidence that we are producing data of some clinical value. It is only by being aware of the true influence of analytical precision on risk, and the contribution that biological variability and other errors such as gestational dating make on estimates of risk, that a more meaningful expression of risk can be provided for an obstetrician counselling a patient.

We agree with $\mathrm{Mr}$ Holding that study days for all involved in screening for Down's syndrome are important at a local level, ' but there is also an urgent need for a national conference on the subject of such screening to discuss some of the issues highlighted in recent weeks in the $B M \mathcal{F}$ and other journals and to establish a national coordinated policy towards screening for Down's syndrome and neural tube defects.

P CARPENTER

Endocrine Unit,

Clinical Biochemistry Department.

Oldchurch Hospital,

Romford,

Essex RM7 0BE

Holding S. Estimations of gestational age and screening for Down's sindrome. BMF 1991:302:965. (20 April.)

Reynolds TM, Penney MD. Fstimations of gestational age and screening for Down's syndrome. BMJ 1991;302:1207. 18 May.)

3 Holding S. Biochemical screening for Down's syndrome. BMF 1991;302:1275. (25 May.)

+ Wald N, Cuckle H, Densem J, et al. Maternal serum screening for Down's syndrome in early pregnancy. BMJ 1988;297: $883-7$

5 Macri JN, Kasturi RV, Kranty DA, et al. Maternal serum Down syndrome screening: free beta protein is a more effective marker than human chorionic gonadotrophin. $4 m$ y Obste Ginnecol 1990);163:1248-53.

6 Spencer $K$. Evaluation of an assay of the free beta subunit of pencer $K$. Evaluation of an assay of the free beta subunit of
choriogonadotrophin and its potential value in screening for Down's sundrome. Clin Chem (in press).

7 Seth J. Ellis A. Report of the UKEQAS pilot study for the EQAS of second trimester $A F P, H C G$ and $U E 3$ in screening for Down's syndrome. London: Department of Health, 1991

8 Spencer K. Analytical error in the calculation of risk in Down's syndrome screening. Proceedings of the Association of Clinical Biochemists national meeting 1991. London: Association of Clinical Biochemsits, 1991:107.

9 Reynolds TM. Software for screening to assess risk of Down's svndrome. BMF 1991;302:965. (20 April.)

\section{Creutzfeldt-Jakob disease and blood transfusion}

SIR, - Though I do not wish in any way to undermine the argument put forward by Drs Marcela Contreras and John Barbara regarding Creutzfeldt-Jakob disease and blood transfusion, their statement that "current criteria for selecting donors in the blood transfusion service ensure that demented subjects and (since 1986) people who have received pituitary extracts are excluded from donating blood as preventive measures" seems to be at odds with the facts.

During a detailed investigation for Today newspaper I spoke to Dr Harold Gunson, the national director of the blood transfusion service, who informed me that it was in 1989 that the service decided to exclude recipients of pituitary extracts "following advice from the Department of Health."

Professor M A Preece, professor of child health and growth at the Institute of Child Health and coauthor of a recent paper on patients treated with human pituitary growth hormone ${ }^{2}$ informed me that he clearly recollected advising the department during 1987-8 that there was a "theoretical risk" from patients given pituitary extracts, but he told me that his advice was not acted on, probably because the department considered the risk to be "forgettably low."

I have also spoken to four recipients of pituitary extracts who donated blood between 1985 and 1989. One of them donated some of that blood in north London during 1987, and the most important donor I have discovered so far made his last contribution in Surrey early in 1989, which earned him a bronze certificate. He stopped donating only because his employment overseas prohibited him from continuing

I would also point out, although it is a different issue, that the last of the recipients of pituitary extract to die from Creutzfeldt-Jakob disease (in December 1990) carried a donor card, neither he nor his parents having been advised of any reason why he should not do so. I know of one other recipient who currently carries such a card.

ALAN M WATKINS

Today,

London E1 9BS

1 Contreras M, Barbara J. Creutzfeldt-Jakob disease and blood ransfusion. B.47 1991:302:1148. 11 M:3y.

2 Buchanan CR, Preece MA, Milner RDG. Mortality, neoplasia, and Creut $/$ feldt-Jakob disease in patients treated with human pituitary growth hormone in the United Kingdom. BMI 1991;302:824-8. (6 April.)

\section{Lithium intoxication}

SIR, - The well documented case of severe lithium toxicity presented by Dr J Goddard' illustrates difficulties in assessing whether neurological complications are due to slow clearing of lithium from the central nervous system or permanent neuronal damage.

Direct measurement of lithium in the brain may require the use of isotopes and neutron irradiation, and in practice the red cell lithium concentration is used instead as an indirect measure of the central nervous system concentration. Red cells and neuronal membranes are thought to have similar properties, ${ }^{3}$ and red cell lithium concentration predicts brain lithium concentration better than plasma lithium concentration does. Thus red cel lithium concentration may explain neurotoxicity during maintenance lithium treatment when plasma lithium concentrations are normal. ${ }^{+}$Neurotoxic concentrations in red cells are lower than those in plasma, beginning at around $0.6 \mathrm{mmol} / \mathrm{l}$. Measuring these concentrations presents problems owing to plasma trapping between the cells. This has led to relatively complex laboratory methods, making the test less readily available,' but recently some colleagues and I have developed a simple, inexpensive technique for measuring red cell lithium concentration that is within the scope of almost all clinical chemistry laboratories."

During the resolution of acute lithium intoxication the fall in neuronal and red cell lithium concentrations may be expected to lag behind that in the plasma owing to lithium's inhibition of its own efflux from the cells by reducing $\mathrm{Li}^{+}-\mathrm{Na}$ counterflow activity. This effect explains why neurological improvement does not occur pari passu with declining plasma concentrations, and such delayed efflux may be discerned in a reported case in which red cell concentrations were monitored during haemodialysis. ${ }^{\times}$Plasma lithium concentrations dropped more rapidly than red cell values during the first two dialysis sessions, pushing up the red cell:plasma ratio to $115 \%$ (normal range $24-28 \%$ ). ${ }^{4}$ At one point there was an upward fluctuation in the plasma concentration perhaps similar to those in the case presented by Dr Goddard, no doubt owing to adjustments between fluid compartments.

It is unfortunte that the Hammersmith team did not measure red cell lithium concentrations. The assessment of the cause of continuing neurological impairment seems to have relied on the use of magnetic resonance imaging, which failed owing to inadequate cooperation in this severely ill patient. Thus assessments of progress were impaired for want of a more basic investigation.

The importance of preventing lithium toxicity through education, highlighted by Dr P F Liddle during the discussion of the case, cannot be overstated. Education of patients is often inadequate at busy psychiatric facilities, where some clinicians may delay explaining how to prevent or deal with toxic effects to patients whom they consider to be already marginally compliant. I have conducted controlled studies of the effects of a balanced programme of education at a typical lithium clinic, in which patients receiving the programme showed a modest improvement in attitude towards their treatment. ${ }^{4}$ The programme doubled patients' knowledge of lithium as shown by a specially designed test such that they compared favourably with professional psychiatric workers, and for items denoting the unsafe use of lithium patients scored half as many errors. These changes, after a single administration of the programme, were well sustained during the six months of the study. In addition, compliance with lithium treatment showed objective evidence of improvement during the programme. ${ }^{10}$

The aim of this programme is to promote the safe and efficient use of lithium because the problems of toxicity arising from lack of information are not infrequent in ordinary psychiatric practice. I hope that this standard programme, consisting of a brief videotape and information pamphlets together with questionnaires to test knowledge and attitudes, will soon become generally available on request.

NORMAN S HARVEY

Department of Psychiatry

Royal Hallamshire Hospital

Sheffield S10 2JF

1 Goddard J. Lithium intoxication. BMF 1991;302:1267-9.

2 Vartsky D, LoMonte A, Ellis KJ, Yasumura S, Cohn SH. A proposed method for in vivo determination of lithium in human brain. Phys Med Biol 1985;30:1225-36.

3 Mendels J, Frazer A. Intracellular lithium concentration and clinical response: towards a membrane theory of depression. f Psychiatr Res 1973;10:9-18.

4 Elizur A, Yeret A, Segal Z, Graff E. Lithium and electrolytes plasma/RBC ratio and paradoxical lithium neurotoxicity. Prog Neuropsychopharmacol Biol Psychiatry 1982;6:235-41.

5 Lewis DA. Unrecognised chronic lithium neurotoxic reactions. FAMA 1983;250:2029-30

6 Summerton AM, Harvey NS, Forrest ARW. New direct method for measuring red cell lithium. $\mathcal{F}$ Clin Pathol 1989;42: 435-7.

7 Rybakowski J, Frazer A, Mendels J. Lithium efflux from erythrocytes incubated in vitro during lithium carbonate administration. Communications in Psychopharmacology 1978;2:105-12.

8 Pringuev D, Yzombard (i, Charbit J-J, Portugal H, Saingra S, Frayssinet $\mathrm{R}$, et al. Lithium kinetics during hemodialsisis in Frayssinet $\mathrm{R}$, et al. Lithium kinetics during hemodialysis in
a patient with lithium poisoning. Am f Psychiatry 1981;138: a patien 2491 .

9 Peet $M$, Harvey NS. Lithium maintenance. 1. A standard education programme for patients. Brf Psychiatry 1991;158: 197-200.

10 Harvey NS, Peet $M$. Lithium maintenance. 2. Effects of personality and attitude on health information acquisition and compliance. Brf Psychiatry 1991;158:200-4.

\section{Lithium and non-steroidal anti-inflammatory drugs}

SIR,-Dr J Goddard points out the danger of lithium intoxication in patients receiving long term treatment with lithium who develop fluid and electrolyte imbalance. ${ }^{1}$ Another potential cause of acute lithium intoxication in these patients is the concomitant use of non-steroidal antiinflammatory drugs. This potentially life threatening drug interaction is illustrated by the following case.

A woman in her early 60 s presented to her general practitioner with a painful left shoulder. She was taking lithium long term for a bipolar affective disorder, and her serum lithium concentrations had been satisfactory. Her general practitioner provisionally diagnosed a frozen shoulder and prescribed ibuprofen $400 \mathrm{mg}$ four times daily. A week later she presented to the accident and emergency department with stupor, confusion, and ataxia. Her serum lithium concentration was $4.2 \mathrm{mmol} / \mathrm{l}$ (therapeutic range $0 \cdot 6-1.2 \mathrm{mmol} / \mathrm{l}$ ), and she had renal failure with a serum creatinine concentration of $500 \mu \mathrm{mol} / \mathrm{l}$. She 